\title{
Association of segmentation of the epididymal interstitium with segmented tubule function in rats and mice
}

\author{
T. T. Turner ${ }^{1,2}$, D. Bomgardner ${ }^{1}$, J. P. Jacobs ${ }^{1}$ and Q. A. T. Nguyen ${ }^{1}$ \\ ${ }^{1}$ Department of Urology and ${ }^{2}$ Department of Cell Biology, University of Virginia School of Medicine, \\ Charlottesville, VA 22908, USA
}

The epithelium of the epididymal tubule has different biological functions in different regions of the tubule. Each region is further organized into lobules or intra-regional segments surrounded by connective tissue septa (CTS). Epididymal segmentation has received little direct attention, yet there is considerable evidence that expression of mRNA and protein often begins or ends precisely at the CTS border of a segment. How such 'on-off' regulation occurs coincident with the passing of the tubule from one segment to the next is unknown. This study examined the segmentation of epididymides in rats and mice. The average adult Sprague-Dawley rat and C57BL/6 mouse caput, corpus and cauda epididymides has seven, two and four, and three, one and two segments, respectively. The apoptosis response of the caput epididymal epithelium to deprivation of lumicrine factors $24 \mathrm{~h}$ after efferent duct ligation in rats and the epididymal expression of a marker protein, $\beta$-galactosidase, in mice were segmented precisely. This validated both at a general response and at a specific protein level that many epididymal functions are regulated within segments. Blue dextran (molecular weight 20000 ) and erythrocine red (molecular weight 880) dyes infused into the interstitial space of specific segments by micropuncture were retained by the CTS of the segments. In similar micropuncture experiments, $\left[{ }^{3} \mathrm{H}\right] \mathrm{H}_{2} \mathrm{O}$ (molecular weight 18) was able to diffuse into an adjacent segment relatively freely whereas $\left[{ }^{14} \mathrm{C}\right]$ polyethylene glycol (molecular weight 4000 ) could not. These studies indicate that the interstitium of intra-regional segments is organized into different physiological compartments and that these compartments play a role in regulating the epididymal epithelium.

\section{Introduction}

In general, epididymal function is androgen dependent (Brooks, 1983; Charest et al., 1988; Robaire and Viger, 1995; Schwidetzky et al., 1997). Androgens are available from luminal fluid as well as from the vasculature (Turner et al., 1984), but other testicular molecules arriving via the ductal lumen also induce epithelial responses (Garrett et al., 1990; Lan et al., 1998). The interplay of the endocrine and lumicrine systems is said to explain how different regions of the single tubule of the epididymis maintain different microenvironments for spermatozoa (Robaire and Viger, 1995). The regions of the epididymis, proximal to distal relative to the testis, are the caput, corpus and cauda. These regions have different patterns of gene or protein expression (Cornwall and Hann, 1995; Kirchhoff, 1999) and different functions relative to sperm maturation and storage (Cornwall et al., 2002). Each epididymal region is further divided into intraregional segments (Abu-Haila and Fain-Maurel, 1984; Kirchhoff, 1999), which consist of lobules of coiled tubule bordered by connective tissue septa (CTS). The

Email: ttt@virginia.edu number of segments in the epididymis varies according to species (see Abe et al., 1983). The epididymal tubule passes through each downstream CTS as it continues into the next distal segment. Epididymal CTS are wellknown but have received little attention because of the assumption that they provide only static, internal support for the organ. Although gene expression and protein synthesis differ among the epididymal regions, as described above, a review of the literature of the last decade demonstrates that these expressions often begin or end precisely at the borders of intra-regional segments (Agrawal et al., 1989; Cornwall et al., 1992; Pera et al., 1994; Sonnenberg-Riethmacher et al., 1996; Lareyre et al., 1999). Comment on this finding has been rare and without detail (Kirchhoff, 1999; Drevet, 2001), yet the bordering of epithelial activities by the CTS of intra-regional segments indicates a more highly ordered segmentation of the epididymal epithelium than is conventionally considered. The question of how epithelial-cell function can be compartmented on the basis of whether the epithelium is on one side or the other of a connective tissue septum has not been addressed.

The fact that the limits of epididymal gene expression or protein synthesis are often coincident with a 
connective tissue septum raises the possibility that CTS have a physiological function relevant to the tubule segments they encapsulate. For example, should CTS have the capacity to retain macromolecules it would raise the possibility that the interstitium of each segment is a separate physiological compartment within which segment-specific paracrine signalling could occur. The present investigation was undertaken to establish the number and variability of intra-regional segments in the epididymides of adult rats and mice, to determine their coincidence with measurable activities of the epididymal epithelium, and to determine whether the CTS provide a barrier function within the epididymal interstitium.

\section{Materials and Methods}

Physical segmentation of the epididymides in rats and mice

Bilateral epididymides of six adult Sprague-Dawley male rats and six adult $\mathrm{C} 57 \mathrm{BI} / 6$ male mice were extirpated from anaesthetized animals (rats: urethane, i.p. injection, $1 \mathrm{mg} \mathrm{g}^{-1}$ body weight; mice: sodium pentabartibal, i.p. injection, $0.1 \mathrm{mg} \mathrm{g}^{-1}$ body weight). Epididymal fat was removed and the tissues were fixed in Bouin's solution. Rat epididymides were halved at mid-corpus and the proximal and distal halves were embedded separately in paraffin wax. Mouse epididymides were embedded intact. Care was taken to embed all tissues so longitudinal sectioning would traverse the entire tissue in-plane. All tissues were sectioned longitudinally and stained with haematoxylineosin. Tissues were examined under a Microphot FXA microscope (Nikon, Tokyo) and images of the tissue were captured with an attached Nikon Coolpix 990 digital camera. Images of each of the 12 epididymides for each species were reproduced in triplicate at approximately $x$ 10 magnification by downloading the images and printing with a laser printer. Three investigators used the printed images to assess independently the location, number and appearance of the CTS in the caput, corpus and cauda epididymides of the rats and mice. Each investigator observed each section through the microscope and traced the CTS as they judged them for each epididymis on their copy of each image. The three investigators' independent tracings of CTS were pooled to construct a single, mean assessment of the number and location of the CTS for that epididymis. Discrepancies, for example, the tracing of a connective tissue septum by one investigator but not by two other investigators, were solved by accepting the judgement of the majority. These images were used to determine the mean number of intra-regional segments for the adult caput, corpus and cauda epididymides for both rats and mice. Significant differences within species and between regions were evaluated by one-way ANOVA followed by the Tukey's range test $(P<0.05)$.

\section{Coincidence of CTS and the limits of specific epithelial activities}

Apoptosis in response to efferent duct ligation (EDL). Efferent ducts of adult male Sprague-Dawley rats $(n=5)$ were bilaterally ligated for $24 \mathrm{~h}$ before extirpation of epididymides and in situ determination of epithelial apoptosis was performed using the terminal deoxynucleotidyl transferase (TdT)-mediated deoxyuridine triphosphate (dUTP)-biotin nick-end labelling (TUNEL) technique (Gavirili and Ben-Sasson, 1992), as described by Turner et al. (1997). Results indicated a segmentspecific apoptosis response in rats (see below), so adult male C57Bl/6 mice $(n=5)$ were also subjected to $24 \mathrm{~h}$ $\mathrm{EDL}$ to determine whether there was a similar occurrence in that species. In this case, epididymal apoptosis was evaluated using the Apostain technique and the F7-26 monoclonal antibody (Alexis Corporation, San Diego, CA) for immunohistochemical localization of nicked, single-stranded DNA in apopotic nuclei described by Lysiak et al. (2000). The association of epithelial apoptotic nuclei beginning or ending coincident with the appearance of a connective tissue septum was noted.

Epithelial $\beta$-galactosidase ( $\beta$-gal) activity. Epididymides from six anaesthetized, adult male mice were removed and fixed intact in $4 \%$ paraformaldehyde for $2 \mathrm{~h}$. The tissues were then processed for $\beta$-gal activity by the $X$-gal technique (Ogawa et al., 1997). Whole mouse epididymides were placed in the $\mathrm{X}$-gal solution (Ogawa et al., 1997) for $8-12 \mathrm{~h}$ at $37^{\circ} \mathrm{C}$, with mild agitation. $\beta$-gal activity was indicated by the development of a blue colour. The reaction was stopped by placing the tissues in $70 \%$ ethanol. The association of blue staining of the tubule beginning or ending coincident with the appearance of a connective tissue septum was noted both by micrography of the intact, stained epididymis and by dissection of the stained epididymis under the dissecting microscope. A combination of sharp and blunt dissection was used to decapsulate the epididymis and to separate the segments of the epididymis along the lines of its apparent CTS borders. The initiation of a colour change of a tubule from blue to white or vice versa and the location of the change relative to the passing of the tubule through a connective tissue septum were noted.

The rat epididymal tunica is too thick to allow sufficient passage of $\mathrm{X}$-gal reagents for whole-mount staining. Instead, epididymides were fixed in $4 \%$ paraformaldehyde overnight then snap-frozen in liquid nitrogen. The frozen tissues were cryosectioned and stained according to the standard X-gal technique, described above, with the exception that staining was carried out in a citric 
acid-phosphate buffer $\left(0.1 \mathrm{~mol}\right.$ citric acid $\mathrm{I}^{-1}+0.2 \mathrm{~mol}$ $\mathrm{Na}_{2} \mathrm{HPO}_{4} \mathrm{I}^{-1}$ ), pH 5.0. Stained cryosections were evaluated for epithelial $\beta$-gal activity in all regions of the epididymis.

\section{Barrier function of CTS}

Dye retention characteristics. Epididymal micropuncture was carried out using techniques previously described (Turner et al., 1981a, 1984; Turner and Bomgardner, 2002), but because of their acute nature, the present experiments were carried out in vitro. Rat epididymides were used because of the tissue-scale requirements for interstitial fluid microsampling. Briefly, epididymides $(n=6)$ were removed from anaesthetized animals and immediately placed in minimum essential medium with Hank's salts (MEM; Gibco, Grand Island, NY) on ice. The epididymal tunica albuginea was punctured with a sharpened, glass micropipette (50 $\mu \mathrm{m}$ tip diameter) within the boundaries of either segments 4 or 5 (Fig. 1a). Over a 5 min period the interstitium of the segment was perfused with $5 \mu \mathrm{l}$ PBS containing either $0.1 \%$ blue dextran (molecular weight 20000; Sigma Chemicals, St Louis, MO) or erythrosin B red dye (molecular weight 836). Perfusion was performed through the micropipette attached to a $50 \mu$ I glass syringe by a length of polyethylene tubing. Perfusion pressure was applied by hand to deliver approximately $1 \mu \mathrm{l}$ per min to prevent pressure build-up within the segment. The epididymides were examined for the presence of dye both within the interstitium of the infused segment and in the interstitia of adjacent segments at 30 and $60 \mathrm{~min}$ after the termination of infusion. In some experiments the same epididymis was perfused with both dye solutions. Results were recorded by micrography.

Retention of radiolabelled molecules. Epididymides $(n=6)$ were obtained and treated as above with the exception that the $5 \mu$ l perfusion fluid contained either $0.05 \mu \mathrm{Ci}\left[{ }^{14} \mathrm{C}\right]$ polyethylene glycol (PEG, molecular weight 4000, $20 \mathrm{mCi} \mathrm{g}^{-1}$; New England Nuclear, Boston, MA) or $0.05 \mu \mathrm{Ci}\left[{ }^{3} \mathrm{H}\right] \mathrm{H}_{2} \mathrm{O}$ (molecular weight 18, $25 \mathrm{mCi} \mathrm{g}^{-1}$; New England Nuclear). Interstitial fluid was collected by micropuncture from both the segment infused and the adjacent, more distal segment at 30 and $60 \mathrm{~min}$ after termination of the $5 \mathrm{~min}$ infusion period. Collection volumes $\geqslant 150 \mathrm{nl}$ of segment-specific interstitial fluid were aliquoted in triplicate $50 \mathrm{nl}$ samples and radioactivity was determined in a liquid scintillation spectrophotometer (LS 5000; Beckman Instruments, Irvine, CA). The mean radioactivity of each epididymal interstitial fluid (EIF) sample was determined and the radioactivity of EIF from the adjacent segment was expressed as a percentage of the radioactivity in the perfused segment at that same time. Significantly different values between times, within compounds, were evaluated by paired $t$ test $(P<0.05)$.
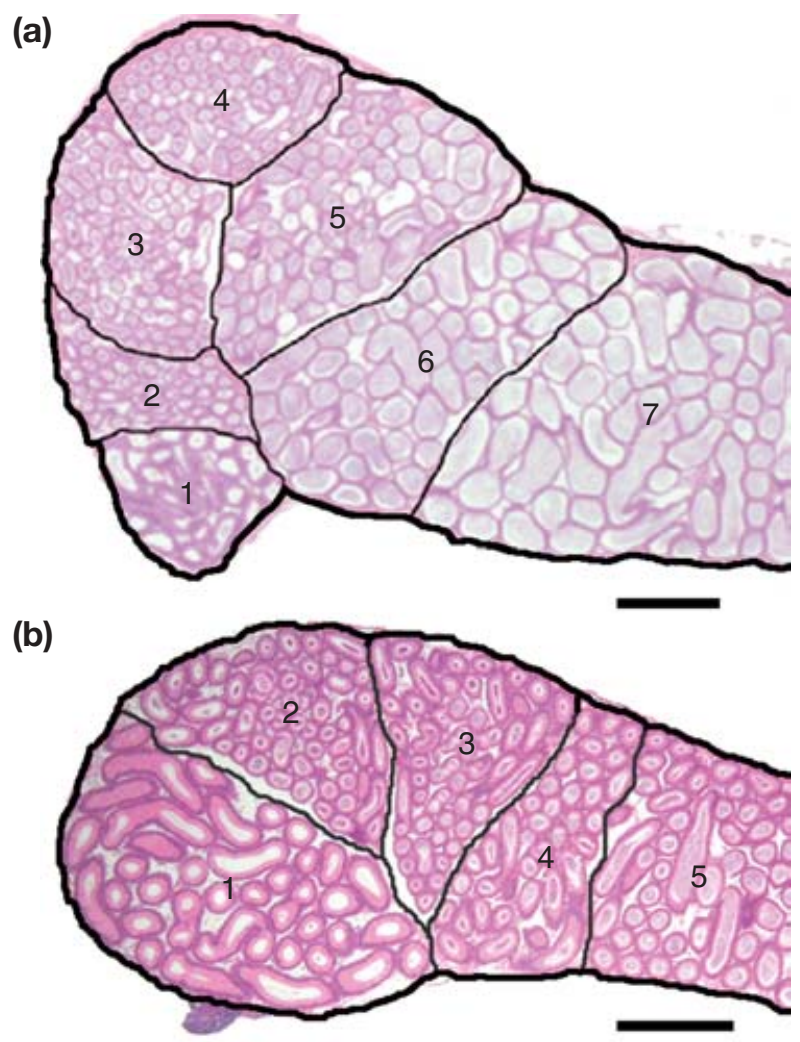

Fig. 1. Intra-regional segmentation of epididymides in rats and mice. Segments shown are numbered from proximal to distal tubule. Connective tissue borders of the segments are highlighted in black. (a) Caput epididymidis in rats. Note that what is conventionally referred to as the 'initial segment' in rats is in fact 3-4 segments. (b) Caput and proximal corpus of the epididymis in mice. What is generally referred to as the initial segment can be one or two physical segments in mice. The segmentations vary somewhat from animal to animal as is implied by the variation in the number of connective tissue septa. Scale bars represent (a) $1 \mathrm{~mm}$ and (b) $500 \mu \mathrm{m}$.

\section{Results}

Physical segmentation of the epididymides in rats and mice

Epididymides in both rats and mice demonstrate CTS dividing regions into segments, which can be numbered from the proximal to the distal parts of the epididymis (Fig. 1). The so-called 'initial segment' of the caput epididymidis in rats actually consists of 3-4 segments, as described here (Fig. 1a), but the 'initial segment' in mice typically consists of one segment (Fig. 1b). The CTS were typically prominent, but there were also connective tissue strands which either did not traverse the entire epididymis to form a complete septum, or which were very 'thin-to-vanishing' as they transversed the tissue (Fig. 2). These connective tissue strands were considered unlikely to be segment-dividing CTS and are reported in Table 1 
Table 1. Number (mean \pm SEM) of connective tissue septa (CTS) dividing the caput, corpus and cauda epididymides in rats and mice into intra-regional segments, and the number of intra-regional semi-septa (SS)

\begin{tabular}{|c|c|c|c|c|c|c|}
\hline \multirow[b]{2}{*}{ Species } & \multicolumn{2}{|c|}{ Caput epididymidis } & \multicolumn{2}{|c|}{ Corpus epididymidis } & \multicolumn{2}{|c|}{ Cauda epididymidis } \\
\hline & CTS & SS & CTS & SS & CTS & SS \\
\hline Rat & $7.1 \pm 0.7^{a}$ & $2.3 \pm 0.4^{\mathrm{a}}$ & $1.6 \pm 0.5^{\mathrm{c}}$ & $1.6 \pm 0.3^{\mathrm{a}}$ & $2.9 \pm 0.4^{\mathrm{b}}$ & $1.6 \pm 0.4^{\mathrm{a}}$ \\
\hline Mouse & $2.5 \pm 0.3^{\mathrm{a}}$ & $1.2 \pm 0.3^{\mathrm{a}}$ & $0.6 \pm 0.2^{\mathrm{C}}$ & $0.0 \pm 0.0^{\mathrm{b}}$ & $1.1 \pm 0.3^{b}$ & $0.4 \pm 0.2^{b}$ \\
\hline
\end{tabular}

a,b,c Means within the same species and septa-type sharing the same superscript are not significantly different $(P<0.05)$.

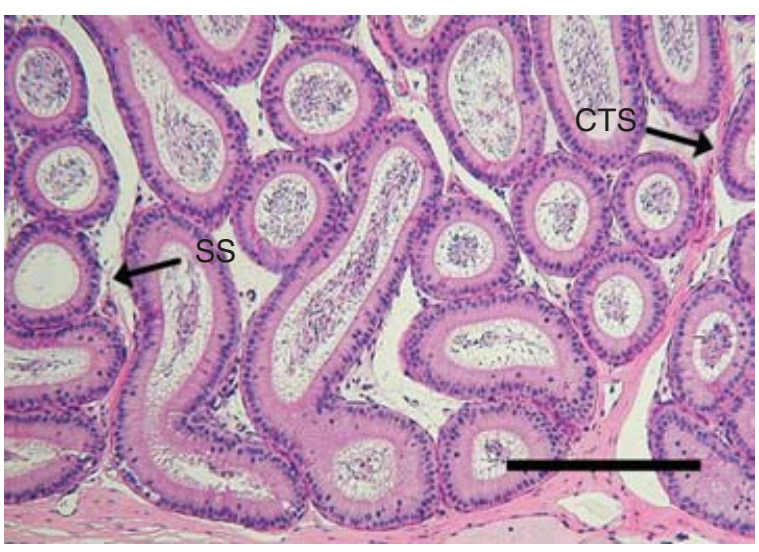

Fig. 2. Connective tissue septa (CTS) in rats and mice were typically prominent sheets of connective tissue separating intraregional segments. Other, less prominent strands of connective tissue were termed semi-septa (SS) and did not clearly provide a separation of the segments. Scale bar represents $225 \mu \mathrm{m}$.

as 'semi-septa'. It is estimated from these data that the average epididymis in rats has 12 CTS dividing the caput, corpus and cauda epididymides into seven, two and four segments, respectively. Likewise, the average mouse epididymis has six CTS dividing the caput, corpus and cauda epididymides into four, one and two segments, respectively. The numbers of CTS and segments do not always match because the same CTS can serve multiple segments and the same septum can be both the end of one region and the beginning of another.

\section{Coincidence of CTS and the limits of specific epithelial activities}

Apoptosis in response to EDL. The epithelium of segment 1 of the epididymis in rats exhibited abundant TUNEL positive nuclei at $24 \mathrm{~h}$ after EDL, but the apoptosis stopped precisely at the CTS separating segment 1 and segment 2 (Fig. 3). Evaluation of the apostained epididymal epithelium in mice at $24 \mathrm{~h}$ after EDL demonstrated the same event; that is, apoptosis of epithelial cells was again limited to the confines of segment 1 (not shown). The epididymal response in rats and mice to deprivation of luminal testicular factors is coincident with CTS borders of intra-regional segments.

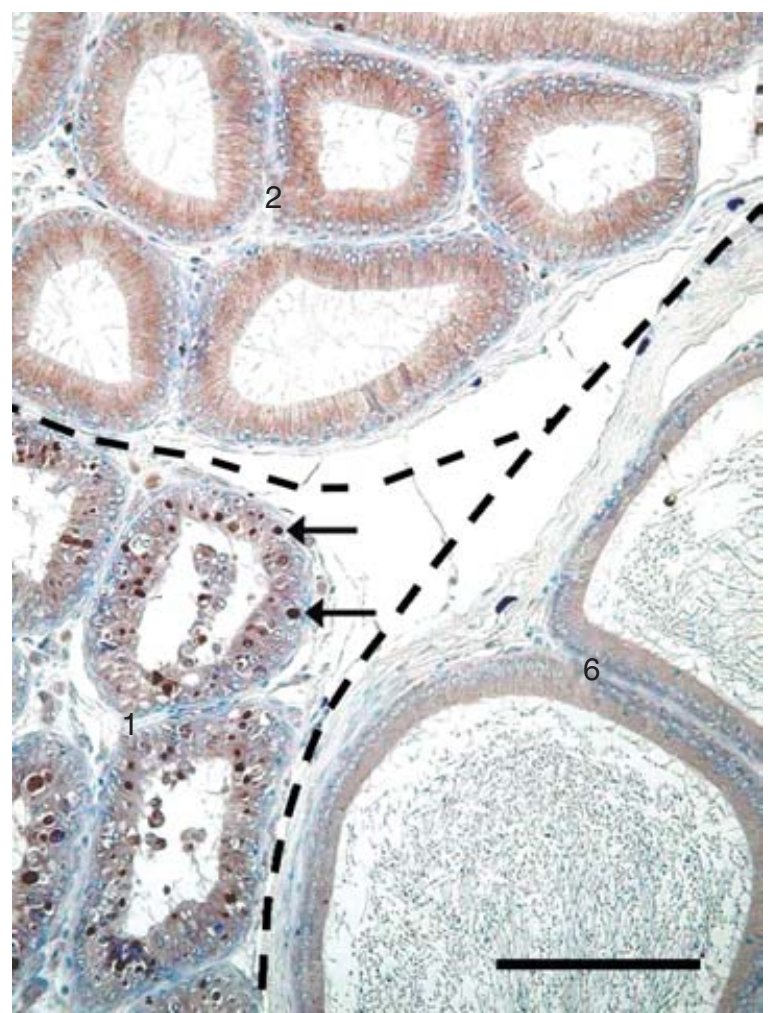

Fig. 3. Epithelial apoptosis after removal of testicular contribution by efferent duct ligation $(E D L)$ in rats, $\times 130$ magnification. Ligation had occurred $24 \mathrm{~h}$ before. Apoptotic nuclei (examples indicated by arrows) are evident in segment 1 but not in segment 2 . The connective tissue septa separating the segments is evident (dashed line). Segment 6 does not show epithelial apoptosis, but $24 \mathrm{~h}$ after $\mathrm{EDL}$, spermatozoa and other testicular contributions are still present in the lumen of that segment. Segments shown are numbered from proximal to distal tubule. Scale bar represents $170 \mu \mathrm{m}$.

\section{Epithelial $\beta$-gal activity}

Activity of $\beta$-gal in the epididymis in mice was expressed in a segmental fashion (Fig. 4). Segment 1 stained intensely for $\beta$-gal activity in all epididymides examined, but staining in the remainder of the caput epididymidis was faint or negative for $\beta$-gal. The demarcation of activity was always at a CTS border. In the epididymis illustrated in Fig. 4, $\beta$-gal activity was re-initiated at the connective tissue septum separating 

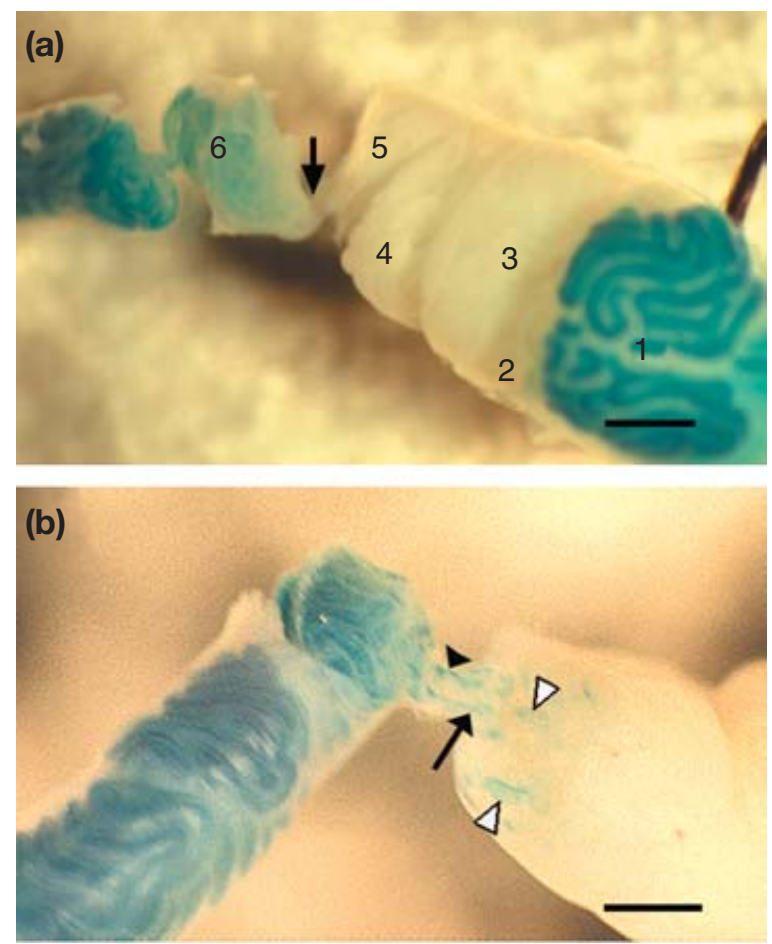

Fig. 4. $\beta$-galactosidase ( $\beta$-gal) staining of the whole-mount epididymis in mice, $\times 15$ magnification. (a) Caput and corpus epididymides in mice dissected to display numbered intraregional segments. Segment 2 is largely hidden behind segment 1 . $\beta$-gal is present in the caput epididymidis in mice in a strictly segmented manner. Segment 1 staining for $\beta$-gal activity is followed by segments that are negative for the enzyme, then there is a sudden upregulation at the connective tissue septum (CTS) between segments 5 and 6 (arrow). $\beta$-gal staining is continuous through segment 6 , which, itself, has been dissected to show continuous staining of tubule. (b) The caput-corpus epididymidis junction in mice (corpus segments positive, caput segments negative) was dissected to illustrate that up- or downregulation of $\beta$-gal in the tubule epithelium occurs as the tubule passes through the CTS (arrow). The exposed length of $\beta$-gal positive tubule (arrowhead) is actually a loop of tubule, and the faint blue staining on the face of the corpus epididymides of the CTS (open arrowheads) is where $\beta$-gal positive tubules were nested before dissection. Scale bars represent (a) $425 \mu \mathrm{m}$ and (b) $340 \mu \mathrm{m}$.

apparent segments 5 and 6 (Fig. 4a). Close examination with microdissection between segments revealed that the $\beta$-gal negative tubule suddenly stained positive as it passed through the CTS (Fig. 4b).

Rat epididymal tubules also expressed $\beta$-gal in a manner delineated by CTS (Fig. 5). Segments 1-3 were faintly positive in the epididymis, but at the CTS separating segments 3 and 4 the $\beta$-gal activity suddenly increased. The relatively intense staining was in segment 4 only. The staining intensity decreased again at the CTS border between segments 4 and 5 (Fig. 5). Segment 5 showed faint staining for $\beta$-gal but segment 6 was completely negative (not shown). At the CTS separating segments 6 and 7 the epithelium suddenly

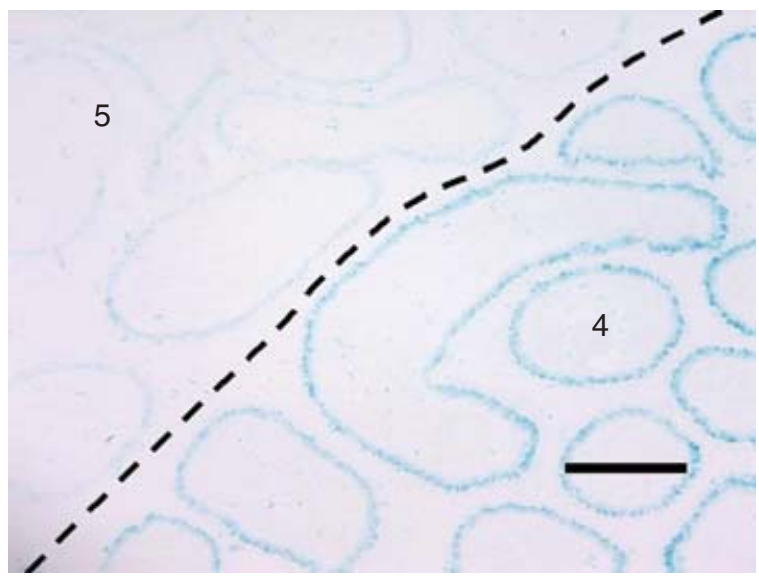

Fig. 5. $\beta$-galactosidase ( $\beta$-gal) staining of cryosections of the caput epididymidis in rats, $\times 50$ magnification. The epithelium of the segment 4 tubule of the caput was positive for the protein but segment 5 was not, a delineation made by the connective tissue septum between the two segments (dashed line). Scale bar represents $350 \mu \mathrm{m}$.

became intensely positive for $\beta$-gal activity again, and staining persisted, though with additional CTS-limited modulations, through the remainder of the epididymis (not shown). The expression of epithelial $\beta$-gal activity in the epididymis in rats and mice is consistent with an intra-regional regulation imparted by CTS.

\section{Barrier function of CTS}

Dye retention characteristics. Blue dextran microperfused under the epididymal tunica was retained by the CTS of the segment perfused (Fig. 6a). The high molecular weight blue dextran and the low molecular weight erythrosine red dye were still retained by segmentlimiting CTS when observed $30 \mathrm{~min}$ after dye perfusion (Fig. 6b), though the erythrosine dye appeared to have begun a minimal diffusion across CTS bordering the segments into which it was perfused. The CTS still retained the high molecular weight blue dextran when observed $1 \mathrm{~h}$ after dye perfusion, but the low molecular weight red dye appeared to have experienced further movement across its CTS (not shown). These qualitative results indicate that CTS may act as a barrier to molecular movement from the interstitial space of one segment to the next.

Retention of radiolabelled molecules. Thirty minutes after infusion of $\left[{ }^{3} \mathrm{H}\right] \mathrm{H}_{2} \mathrm{O}$ into the interstitial space of an intra-regional segment, isotope concentrations in the EIF of the adjacent, downstream segment (EIF-2) were approximately $25 \%$ of the isotope concentrations in the contemporaneously collected EIF of the originally infused segment (EIF-1). One hour after $\left[{ }^{3} \mathrm{H}\right] \mathrm{H}_{2} \mathrm{O}$ infusion isotope concentrations in EIF-2 had reached over $40 \%$ of the concentrations in EIF-1 (Fig. 7). In contrast, $30 \mathrm{~min}$ 

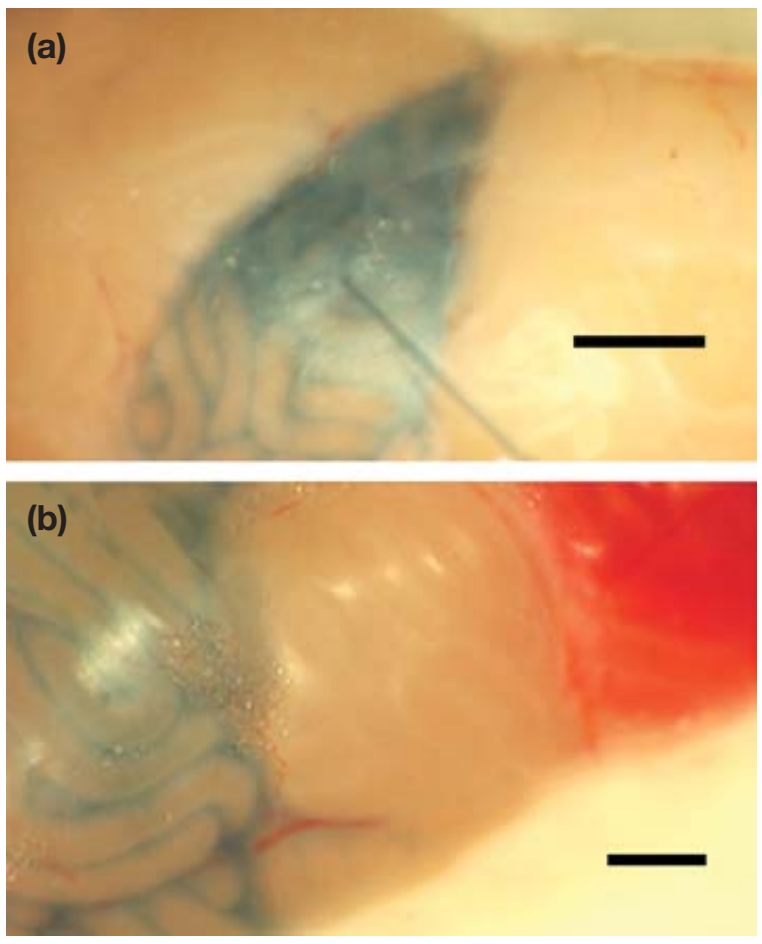

Fig. 6. Dye retention by segments of the epididymis in rats, $\times 30$ magnification. (a) Blue dextran (molecular weight 20000 ) infused into the interstitial space of an epididymal segment by a micropuncture pipette (arrow) is retained by the connective tissue septa (CTS; arrowheads) of that segment. (b) Blue dextran and erythrocine red (molecular weight 880) infused in different segments are still retained within the $\mathrm{CTS}$ at $30 \mathrm{~min}$ after infusion. The erythrocine dye shows some evidence of beginning to penetrate the CTS, illustrating a size-related capacity for diffusion. The red line near the blue dextran-stained segment is a blood vessel. Scale bar represents $700 \mu \mathrm{m}$.

and $1 \mathrm{~h}$ after infusion of $\left[{ }^{14} \mathrm{C}\right] \mathrm{PEG}$ into a segment, EIF-2 isotope concentrations were only $6 \%$ and $5 \%$, respectively, of those in contemporaneously collected EIF-1 (Fig. 7). These results demonstrate quantitatively the ability of the CTS to retain large molecules $(20 \mathrm{kDa}$, $4 \mathrm{kDa}$ ) within the interstitium of a given segment, and this occurs more restrictively than for smaller molecules (0.9 kDa, $0.02 \mathrm{kDa})$.

\section{Discussion}

The caput, corpus and cauda epididymides in rats and mice are organized into a series of intra-regional segments. Although this segmentation has been recognized for many years, including the foundational work of Reid and Cleland (1957), it has not received the attention of an occurrence likely to be of physiological or cellbiological consequence. It has become increasingly evident, however, that epithelial gene and protein expressions commonly experience some 'on-off switch' precisely at a CTS border (see for example, Agrawal

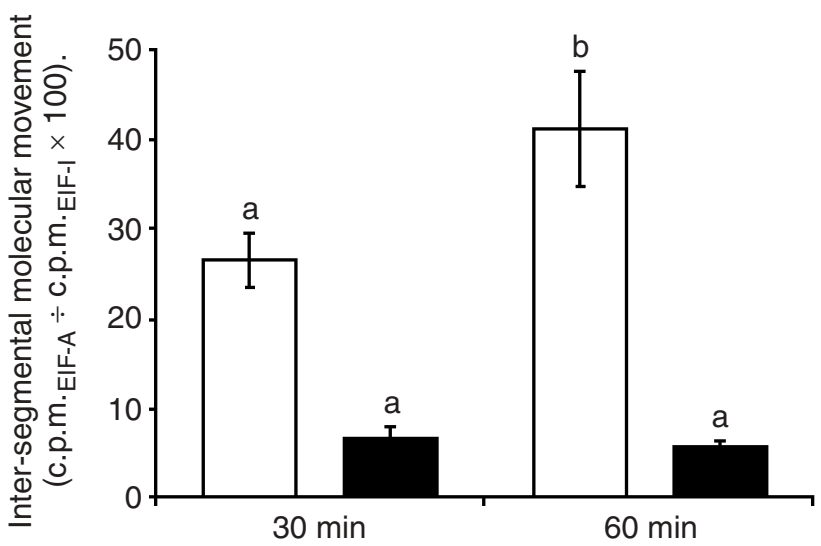

Fig. 7. Retention of radiolabelled, inert compounds of different molecular weights by connective tissue septa (CTS) in rats. Movement of molecules across the CTS is illustrated by the concentration of radioactivity in epididymal interstitial fluid of the adjacent segment (EIF-A) relative to the radioactivity of the EIF of the infused segment (EIF-I) collected at the same time (mean \pm SEM). Movement of $\left[{ }^{14} \mathrm{C}\right]$ polyethylene glycol (molecular weight 4000 ; - ) out of the infused segment was restricted whereas $\left[{ }^{3} \mathrm{H}\right] \mathrm{H}_{2} \mathrm{O}(\square)$ diffused more freely within compounds. Columns with different superscripts are significantly different from each other $(P<0.05)$.

et al., 1989; Pera et al., 1994; Lareyre et al., 1999). This finding indicates that for at least some genes and proteins there must be a method for regulating expressions within the segment borders. These observations arise from the published results of others and are from studies not designed with the specific issue of segmentation in mind. Consequently, the present study aimed to determine fundamental information about epididymal segmentation in the epididymides in rats and mice. Epididymides were specifically examined for: (1) the number and variability of intra-regional segments; (2) the coherence between the segmented structure of the epididymis and its response to a biological stimulus; (3) coherence between segmented structure and the presence of a model protein ( $\beta$-gal); and (4) the ability of the CTS to retain segment-specific interstitial molecules.

The number of epididymal CTS varies among species, but the present results demonstrate that the number of segments within species also exhibits some variability. A portion of the variability within species was due to natural variation in segment size and location, but some of the variation was likely to be due to the judgement of investigators in deciding from histological sections alone what constituted a CTS in a given section. Septa across longitudinal sections were not all equally prominent, and it was not unusual that judgements would have to be made in deciding if a questionable connective tissue strand was a septum that was less prominent than usual or a semi-septum that was more prominent than usual. It is speculated that semi-septa are part of the internal architecture of the epididymis lending structural integrity 
in addition to the CTS. The aim of the present study was to identify as CTS only septa that truly divided the epididymal regions into segments like those illustrated by partial dissection.

It was tempting to assign a correlation in the epididymis in rats between segment number and the epithelial zones described by Reid and Cleland (1957). It would be easy, for example, to associate segments 1 , 2 and 3 with Reid and Cleland's zones 1a, 1b and 1c. However, assigning physical segment with epithelial zone thereafter becomes more problematical. In any case, epithelial zone and epididymal segmentation are not invariably synonymous. Likewise, the numbered mouse segments of this study appear similar to those of Abe et al. (1983) and Abou-Haila and Fain-Maurel (1984), though strict identity throughout the epididymis is uncertain. Segmentation was not the main focus of Abe et al. (1983), and Abou-Haila and Fain-Maurel (1984) studied only the caput epididymidis.

Orientation of the tissue in the section could also lead to variation in the count of CTS or segments, but orientation of the tissue to the plane of sectioning was largely controlled for in the present study. In addition, serial, longitudinal sectioning of a mouse epididymis from dorsal to ventral surface demonstrated that, although viewing sections at different depths within the same epididymis can change the apparent size of a segment, it is unlikely to change the judgement of whether a particular septum is present. Segments are often wedge-shaped and may appear smaller or larger depending on where in the wedge the section was taken, but the presence of the CTS around the wedge remains equally apparent.

Nicander et al. (1983) originally reported an apoptosis-like response of the rat epididymis after EDL, and this was more recently verified by specific techniques for detection of apoptosis (Fan and Robaire,1998; Turner and Riley, 1999). Segments 1 and 2 of the epididymis in rats are well-cleared of testicular contribution at $24 \mathrm{~h}$ after EDL (Turner and Riley, 1999), but epithelial apoptosis is limited at the CTS border of segment 1 . This response to a physiological (or pathological) stimulus illustrates a vigorous dynamic between the epithelium and its luminal content, and it demonstrates a precise control over tubular events at the point in the epididymal tubule where it passes from one segment to another, that is, at the CTS.

$\beta$-gal was used as a model protein, the presence and apparent segmentation of which in the epididymal epithelium was previously apparent (SonnenbergRiethmacher et al., 1996); however, the segmentation of that activity, as opposed to its regionalization, has not been commented on and the segmentation pattern of the protein throughout the epididymis was uncertain. Importantly, its coincidence with CTS borders had not been examined. The present results in both rats and mice demonstrate that the presence of $\beta$-gal in the epididymal epithelium occurs in a highly segmented fashion and, further, that segmentation in the epithelium is coincident with the segmentation of the interstitium imposed by CTS. Thus, an epithelial response to stimulus, that is, apoptosis after loss of lumicrine factors, and the distribution of a model epithelial protein, that is, $\beta$-gal, both occur in a segmented manner within the tubule epithelium. This segmentation of the tubule is coincident with segmentation of the epididymal interstitium and indicates that the two may be related.

It is hypothesized that CTS divide regions into separate physiological compartments wherein segment-specific interstitial microenvironments can be maintained. Such compartmentation could allow paracrine signalling between stromal cells and the tubule epithelium. Such signalling in one compartment could be different from that in an adjacent compartment, and this could explain the 'switch' at the CTS which turns on or off certain gene or protein expressions in the epididymal epithelium. For this to be the case, the CTS must have the ability to retain macromolecules. The ability of the CTS to restrict the movement of selected molecules from the interstitium of one segment to the next was determined to examine this possibility.

Dye molecules injected intra-segmentally with micropuncture pipettes were clearly retained by the CTS and CTS had the ability to restrict molecular movement of both large and relatively small dyes. Nevertheless, molecules of approximately $0.88 \mathrm{kDa}$ experience limited diffusion across the CTS at the times observed. This qualitative impression was substantiated in studies of similar design but using inert, radiolabelled compounds for intra-segmental infusion rather than dyes.

$\left[{ }^{3} \mathrm{H}\right] \mathrm{H}_{2} \mathrm{O}$ diffused readily across the CTS of the infused segment reaching an average concentration in the EIF of the adjacent segment of over $40 \%$ of that in the EIF of the infused segment at $1 \mathrm{~h}$ after infusion. In contrast, $\left[{ }^{14} \mathrm{C}\right] \mathrm{PEG}$ has a molecular mass in the range of many growth factors and was retained by the CTS bordering the infused segment. Concentrations of $\left[{ }^{14} \mathrm{C}\right] \mathrm{PEG}$ in the EIF of the adjacent segment were approximately $6 \%$ of those in the EIF of the infused segment at $1 \mathrm{~h}$ after infusion. In micropuncture experiments evaluating the ability of the blood-testis or blood-epididymal barrier to restrict molecular movement from blood-to-tubule lumen, an intra-luminal isotope concentration of $5 \%$ or less of that in serum collected at the same time has been considered to be a background value, indicating essentially no movement between compartments (Turner et al., 1981a,b). Thus, it is concluded that the CTS have the ability to restrict the movement of molecules with molecular masses in the range of common growth factors and other proteins. This result implies that interstitial microenvironments might be different in adjacent segments of the epididymis with CTS having the ability to limit diffusion of interstitial factors released within a given segment. Furthermore, this indicates 
that cell signalling between epididymal stroma and epithelium could be segment-specific and could be a mechanism by which the precisely segmental activities of the tubule epithelium are regulated. This possibility is under further investigation in the authors' laboratory.

This work was supported by NIH grant DK45179 and grant HD28934 supporting the University of Virginia's Center for Research in Reproduction. Special appreciation is expressed to the Cell Science Core of that center for assistance with histology and to J. Fenell for his assistance with the microperfusion studies.

\section{References}

Abe K, Takano H and Ito T (1983) Ultrastructure of the mouse epididymal duct with special reference to the regional differences of the principal cells Archivum Histologium Japonicum 46 51-68

Abou-Haila A and Fain-Maurel MA (1984) Regional differences of the proximal part of the mouse epididymis Anatomical Record 209 197-208

Agrawal YP, Peura T and Vanha-Perttula T (1989) Distribution of $\gamma$-glutamyl transpeptidase in the mouse epididymis and its response to acivicin Journal of Reproduction and Fertility 86 185-193

Brooks DE (1983) Effect of androgens on protein synthesis and secretion in various regions of the rat epididymis as analyzed by 2 dimensional gel electrophoresis Molecular and Cellular Endocrinology 27 $255-270$

Charest NJ, JosephI DA, Wilson EM and French FS (1988) Molecular cloning of complementary deoxyribonucleic acid for an androgenregulated epididymal protein: sequence homology with metallo-proteins Molecular Endocrinology 2 999-1004

Cornwall GA and Hann SR (1995) Specialized gene expression in the epididymis Journal of Andrology 16 379-383

Cornwall GA, Orgebin-Crist MC and Hann SR (1992) The CRES gene: a unique testis regulated gene related to the cystatin family is highly restricted in its expression to the proximal region of the mouse epididymis Molecular Endocrinology 6 1653-1664

Cornwall GA, Lareyre JJ, Matusik R J, Hinton BT and Orgebin-Crist MC (2002) Gene expression and epididymal function. In The Epididymis: From Molecules to Clinical Practice pp 169-200 Eds B Robaire and BT Hinton. Kluwer Academic/Plenum Publishers, New York

Drevet JR (2001) Regulation of gene expression in epididymis. In Andrology in the Twenty-First Century pp 199-214 Eds B Robaire, H Chemes and CR Morales. Medimond Publishing, Englewood

Fan XP and Robaire B (1998) Orchidectomy induces a wave of apoptotic cell death in the epididymis Endocrinology 139 2124-2136

Garrett JE, Garrett SH and Douglass J (1990) A spermatozoa-associated factor regulates proenkephalin gene expression in the rat epididymis Molecular Endocrinology 4 108-118

Gavirili Y and Ben-Sasson SA (1992) Identification of programmed cell death in situ via specific labeling of nuclear DNA fragmentation Journal of Cell Biology 119 493-501

Kirchhoff C (1999) Gene expression in the epididymis International Review of Cytology 188 133-202

Lan ZJ, Labus JC and Hinton BT (1998) Regulation of gamma-glutamyl transpeptidase catalytic activity and protein level in the initial segment of the rat epididymis by testicular factors: role of basic fibroblast growth factor Biology of Reproduction $\mathbf{5 8}$ 197-206

Lareyre JJ, Thomas TZ, Zheng WL, Kasper S, Ong PE, Orgebin-Crist MC and Matusik RJ (1999) A 5-kilobase-pair promoter fragment of the murine epididyma I retinoic acid-binding protein gene drives the tissue-specific, cell-specific, and androgen regulated expression of a foreign gene in the epididymis of transgenic mice Journal of Biological Chemistry $\mathbf{2 7 4}$ 8282-8290

Lysiak JL, Turner SD and Turner TT (2000) Molecular pathway of germ cell apoptosis following ischemia/reperfusion of the rat testis Biology of Reproduction 63 1465-1470

Nicander L, Osman DI, Pløen L, Bugge HP and Kvisgaard KN (1983) Early effects of efferent ductule ligation of the proximal segment of the rat epididymis International Journal of Andrology 6 91-102

Ogawa T, Arechaga JM, Averbock MR and Brinster RL (1997) Transplantation of testis germinal cells into mouse seminiferous tubules International Journal of Developmental Biology 41 111-122

Pera I, Ivell R and Kirchhoff C (1994) Regional variation of specific gene expression in the dog epididymis as revealed by in situ transcript hybridization International Journal of Andrology 17 324-330

Reid BL and Cleland KW (1957) The structure and function of the epididiymis. I. The histology of the rat epididymis Australian Journal of Zoology 5 223-246

Robaire B and Viger RS (1995) Regulation of epdidymal epithelial cell function Biology of Reproduction 52 226-236

Schwidetzky U, Schleuning WD and Haendler B (1997) Isolation and characterization of the androgen-dependent mouse cysteinerich secretoryprotein-1 (CRISP-1) gene Biochemical Journal 321 325-332

Sonnenberg-Riethmacher E, Walter B, Riethmacher D, Godecke S and Birchmeier C (1996) The c-ros tyrosine kinase receptor controls regionalization and differentiation of epithelial cells in the epididymis Genes and Development 10 1184-1193

Turner TT and Bomgardner D (2002) On the regulation of Crisp-1 mRNA expression and protein secretion by luminal factors presented in vivo by microperfusion of the rat proximal caput epididymides Molecular Reproduction and Development 61 437-444

Turner TT and Riley TA (1999) p53 independent, region-specific epithelial apoptosis is induced in the rat epididymis by deprivation of luminal factors Molecular Reproduction and Development 53 188-197

Turner TT, D'Addario DA and Howards SS (1981a) The blood epididymal barrier to $\left[{ }^{3} \mathrm{H}\right]$-inulin in intact and vasectomized hamsters Investigative Urology 19 89-91

Turner TT, Giles RD and Howards SS (1981b) Effect of oestradiol valerate on the rat blood-testis and blood-epididymal barriers to $\left[{ }^{3} \mathrm{H}\right]$ inulin Journal of Reproduction and Fertility 63 355-358

Turner TT, Ewing LL, Jones CE, Howards SS, Zegeye B and Gunsalus G (1984) On the androgen microenvironment of maturing spermatozoa in the adult rat Endocrinology 115 1925-1932

Turner TT, Tung KSK, Tomomasa H and Wilson LW (1997) Acute testicular ischemia results in germ cell-specific apopotosis in the rat Biology of Reproduction $\mathbf{5 7}$ 1267-1274

Received 12 December 2002.

First decision 7 February 2003.

Revised manuscript received 13 February 2003.

Accepted 25 February 2003. 